\title{
Comparative Performance Analysis of Different Routing Protocols in Wireless Ad-hoc networks (IEEE 802.11)
}

\author{
${ }^{1}$ Mahendra Kumar, ${ }^{2}$ A. K. Jain \\ ${ }^{1}$ Research Scholar, Department of Instrumentation and Control Engineering, \\ Dr. B R Ambedkar National Institute of Technology Jalandhar, Punjab-144011, India \\ E-mail: dei.mahendra@gmail.com \\ ${ }^{2}$ Professor and Head, Department of Instrumentation and Control Engineering, \\ Dr. B R Ambedkar National Institute of Technology Jalandhar, Punjab-144011, India \\ E-mail: jainak@nitj.ac.in
}

\begin{abstract}
Wireless Ad-hoc networks have lack of mass deployment. An Ad hoc wireless network has a dynamic nature that leads to constant changes in its network topology. There is an infrastructure less and decentralized network which need a robust dynamic routing protocol. This article presents performance comparison of wireless Ad-hoc network on different routing protocols. Network simulator QualNet 5.0.2 has been used to evaluate the performance of wireless networks with various routing protocols.
\end{abstract}

\section{Key words}

Average End to End delay, Average Jitter, Throughput, Average Queue Length, Average time in queue, Average Hop counts, WLAN.

\section{SUBJECT CLASSIFICATION}

Wireless Networking, Computer Networking and Electronics Instrumentation

\section{TYPE (METHOD/APPROACH)}

In this work, network simulator QualNet 5.0.2 has been used to evaluate the performance of wireless networks with various routing protocols

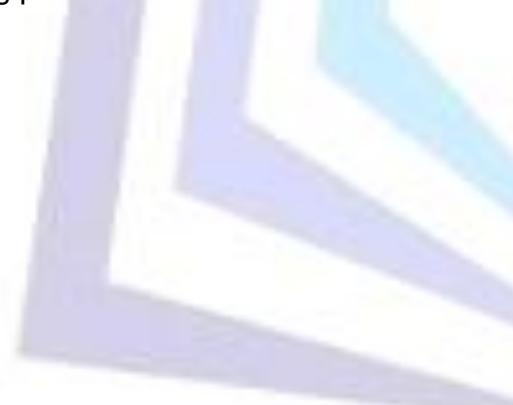

\section{Council for Innovative Research}

Peer Review Research Publishing System

Journal: INTERNATIONAL JOURNAL OF COMPUTERS \& TECHNOLOGY

Vol 8, No 3

editor@cirworld.com

www.cirworld.com, member.cirworld.com 


\section{INTRODUCTION}

A wireless Ad hoc network is a collection of wireless nodes which are able to communicate with each other without relying on predefined infrastructures. There is no static infrastructure such as base stations. Each node in the network also acts as a router, forwarding data packets to other nodes [1].

The popularity of WLANs is growing due to improvement in transmission speed, flexibility and low cost infrastructure. The convenience of wireless networking has led IEEE 802.11 to emerge from the individual home to large-scale deployments in environments covering medium to large enterprises, apartment complexes and housing Developments, and public area hotspots [2]. Wireless technologies are being widely used in lot many applications such as communications, entertainment, medical, battle fields and institutes etc. Wireless technology is based upon the principle of direct/indirect communication between two or more point by radio waves technology. Many researches on routing protocols for ad hoc networks have been led, and several protocols have emerged. They can be classified into three main categories: the proactive, reactive, and hybrid protocols [3]. Routing protocols for wireless networks have to face the challenge of frequently changing topology, low transmission power and asymmetric links. There are more routing protocols used in wireless LAN for improving Quality of Service (QoS). There are more routing protocols used in wireless LAN for improving Quality of Service (QoS). This paper presented some routing protocols to improving the performance of Wireless LAN i.e. as Anonymous On-Demand Routing protocols (ANODR), Ad hoc On-demand Distance Vector (AODV), Dynamic Source Routing (DSR), Dynamic MANET OnDemand (DYMO), Landmark Routing protocols (LANMAR), Inter-zone Routing Protocol (IERP) and Zone Routing Protocol (ZRP).

In section II, overview of IEEE 802.11 has discussed. Overview of routing protocols used in wireless network has given in section III. Simulation setup of WLAN with different routing protocols is provided in section IV. Result is discussed in section V. Last conclusion of wireless networks is discussed in section VI.

\section{OVERVIEW OF IEEE $\mathbf{8 0 2 . 1 1}$}

IEEE 802.11 standard was first introduced in 1997. It was envisioned for home and office environments for wireless local area connectivity and supports three types of transmission technologies namely i) Infrared Radiation(IR), ii) Frequency Hopping Spread Spectrum (FHSS), iii) Direct Sequence Spread Spectrum (DSSS). In 1999 two other transmission technologies were included as i) Orthogonal Frequency Division Multiplexing (OFDM) and ii) High Rate-Direct Sequence Spread Spectrum (HRDSSS). IEEE 802.11 has two different access methods, the mandatory Distributed Coordinator Function (DCF) and the optional Point Coordinator Function (PCF).

\subsection{Distributed coordinator function}

The DCF is the basic access mechanism of IEEE 802.11. It uses a Carrier Sense Multiple Access with Collision Avoidance (CSMA/CA) algorithm to mediate the access to the shared medium. Before a data frame is sent, the station senses the medium. If it is idle for at least a DCF interframe space1 (DIFS) period of time, the frame is transmitted. Otherwise, a backoff time $\mathrm{B}$ (measured in time slots) is chosen randomly in the interval [0, CW], where CW is the so called Contention Window [4].

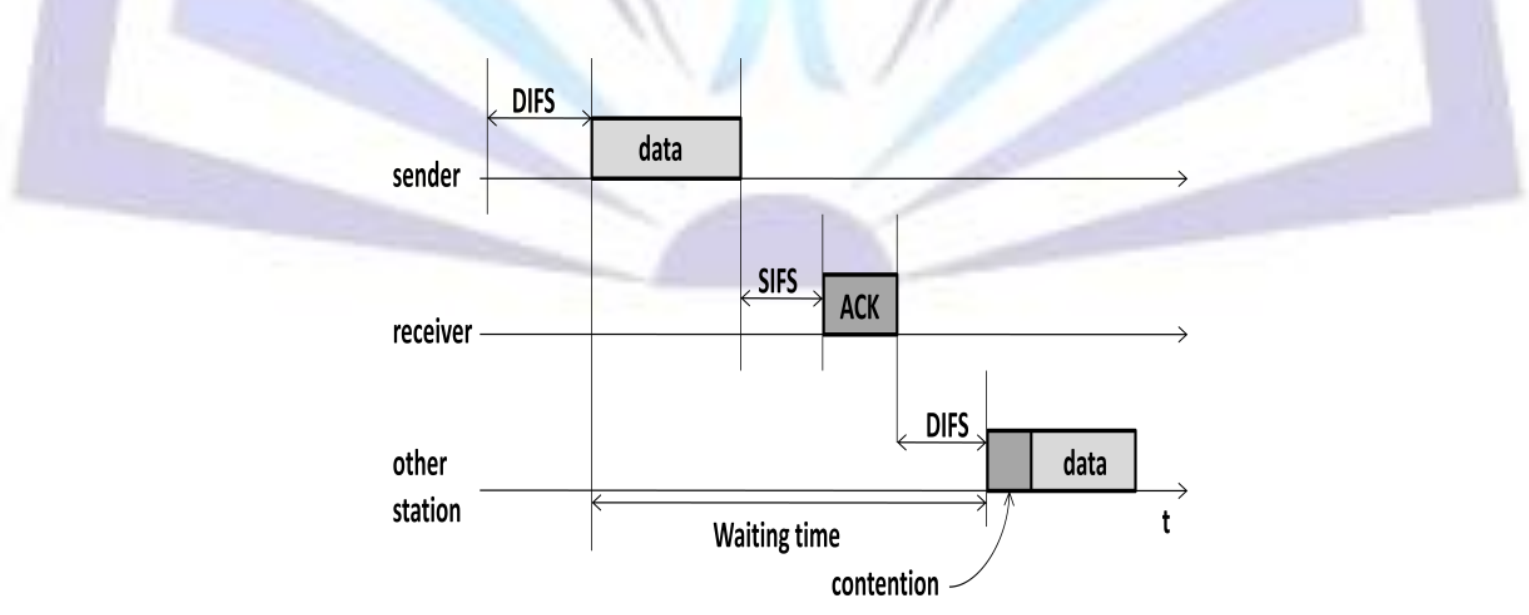

Fig.1 Distributed coordinator function

After the medium has been detected idle for at least a DIFS, the backoff timer is decremented by one for each time slot the medium remains idle. If the medium becomes busy during the backoff process, the backoff timer is paused, and is restarted 
when the medium has been sensed idle for a DIFS again. When the backoff timer reaches zero, the frame is transmitted. Upon detection of a collision (which is detected by the absence of an acknowledgment frame to the data frame), the contention window is doubled according to

$$
\mathrm{CWi}=2^{\mathrm{k}+\mathrm{i}-1}-1
$$

Where $\mathrm{i}$ is the number of attempts to transmit the frame that has been done, and $\mathrm{k}$ is a constant defining the minimum contention window, CWmin $=2^{\mathrm{k}}-1$ as given in Fig.1.

\subsection{Point coordinator function}

PCF is a centralized, polling-based access mechanism which requires the presence of a base station that acts as Point Coordinator (PC). The point coordinator in access point splits the access time into superframe periods as shown in Fig. 2. A superframe comprises a Contention Free Period (CFP) and a Contention Period (CP). At time t0 the CFP of the superframe should theoretically start, but another station is still transmitting data. After the medium has been idle until t1, the point coordinator has to wait for PCF Interframe Spacing (PIFS) before accessing the medium. As PIFS is smaller than DIFS, no other station can start sending earlier. The point coordinator now sends data D1 downstream to the first wireless station. This station can answer at once after SIFS. After waiting for SIFS again, the point coordinator can poll the second station by sending D2. This station may answer upstream to the coordinator with data U2. Polling continues with the third node. This time the node has nothing to answer and the point coordinator will not receive a packet after SIFS. After waiting for PIFS, the coordinator can resume polling the stations. Finally, the point coordinator can issue an end marker (CFend), indicating that the contention period may start again. Using PCF automatically sets the Net Allocation Vector (NAV), preventing other stations from sending.

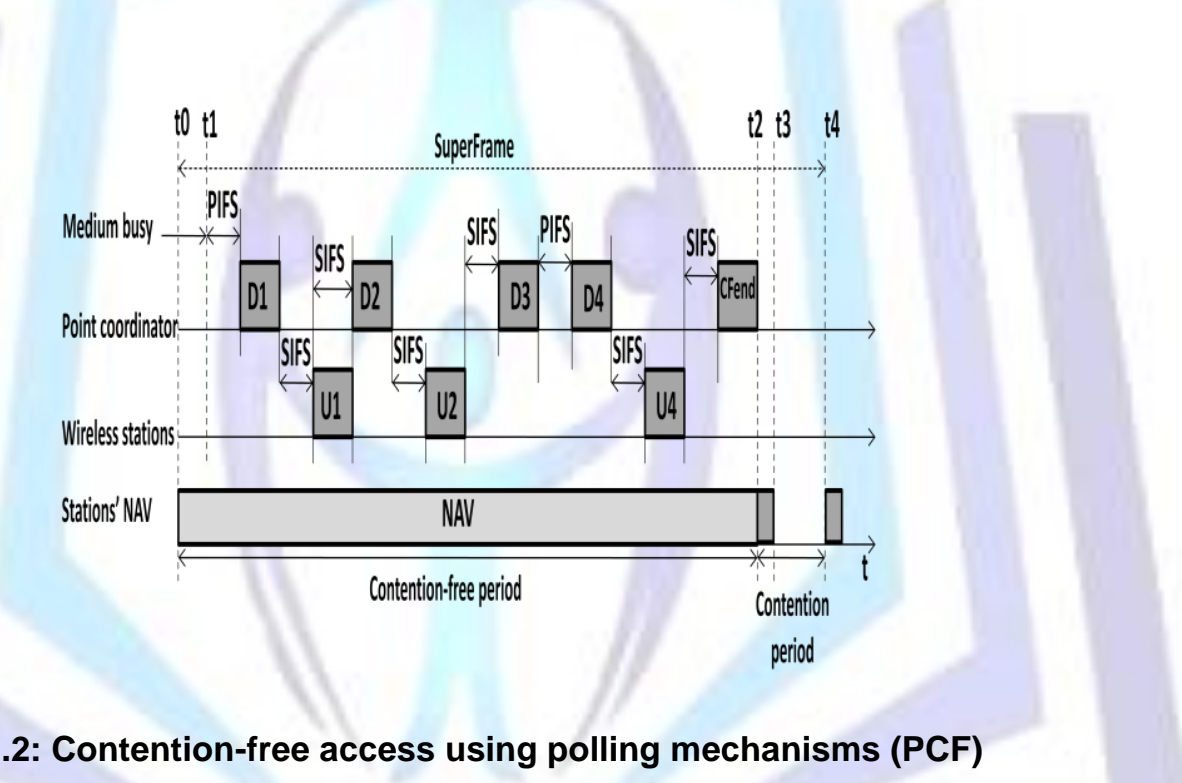

between PCF data frames is shorter than the usual DIFS. This space is called a PCF interframe space (PIFS). To prevent starvation of stations that are not allowed to send during the CFP, there must always be room for at least one maximum length frame to be sent during the contention period.

\section{OVER VIEW OF ROUTING PROTOCOLS}

Ad-hoc routing protocols can be divided into three categories, Proactive (Table driven) routing protocol, Reactive (On demand) routing protocol and Hybrid routing protocol as given in Fig. 3 [6]. Proactive routing protocols maintain information continuously. Typically, a node has a table containing information on how to reach every other node and the algorithm tries to keep this table up-to-date. Proactive protocols use excess bandwidth by attempt to maintain the routes information to all other nodes and by propagating any changes in the network topology throughout the entire network. Reactive routing involves long route request delays. Reactive routing also inefficiently floods the entire network for route determination. In this routing protocol, information is acquired on-demand. This is the route discovery operation. Route maintenance is the process of responding to change in topology that happen after a route has initially been created. Hybrid routing protocol combines the best features of the above two protocols. Nodes within certain distance, from the node concerned, or within a particular geographical region, are said to be within the routing zone of the given nodes. For routing within this zone, a table-driven approach is used. For nodes that are located beyond this zone, an on-demand approach is used. 


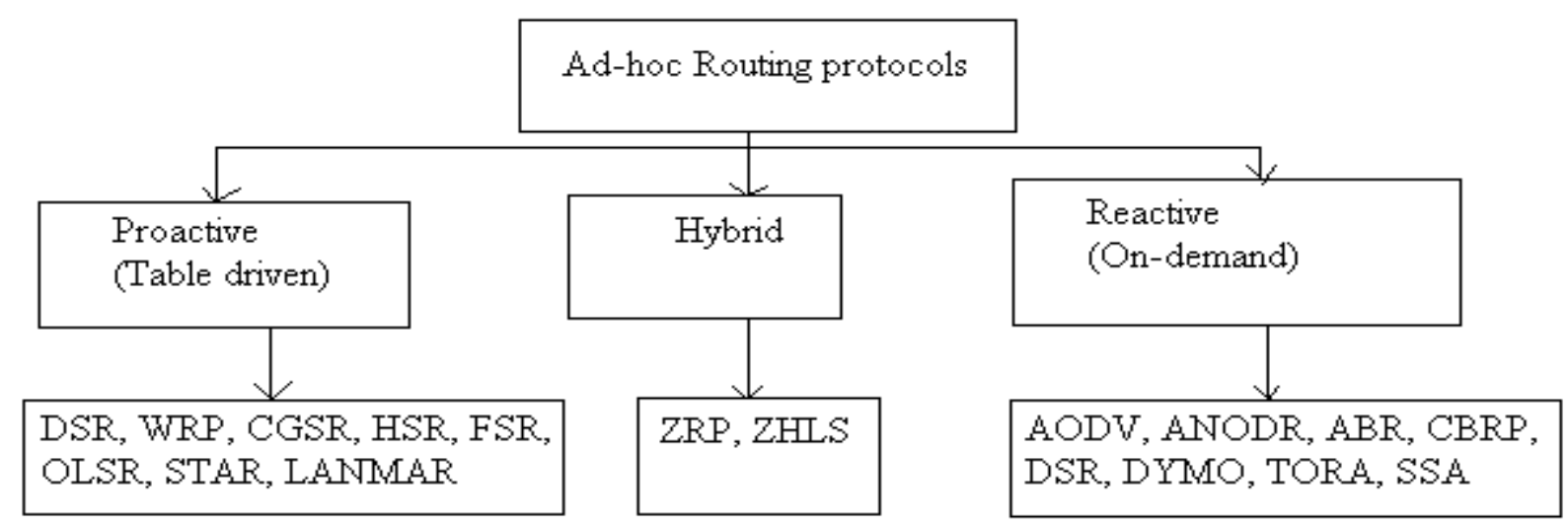

DSDV: Destination-Sequenced Distance-Vector Routing WRP: Wireless Routing Protocol CGSR: Clusterhead Gateway Switch Routing HSR: Hybrid source routing protocol FSR: $\quad$ Fisheye State Routing OLSR: Optimized Link State Routing Protocol STAR: $\quad$ Source-Tree Adaptive Routing LANMAR: Landmark Ad-hoc Routing Protocol TORA: Temporally-Ordered Routing Algorithm
ZRP: Zone Routing Protocol

ZHLS: Zone-based Hierarchical Link State

AODV: Ad hoc On-Demand Distance Vector

ANODR: anonymous on-demand routing

ABR: Associativity-Based Routing

CBRP: Cluster Based Routing Protocol

DSR: Dynamic source routing protocol

DYMO: Dynamic MANET On-demand

SSA: $\quad$ Signal Stability based Adaptive

Fig.3 Classification of Ad-hoc Routing Protocols

There are many routing protocols used for Ad-hoc network are following

\subsection{Anonymous On-Demand Routing protocols (ANODR)}

Liu Yang et al (2006) proposed an approach- discount ANODR for anonymous on demand routing in mobile ad hoc networks [7]. ANODR is identity free, i.e. it does not use the nodes' identities but it exploits a route pseudonymity approach to address the route untraceability problem. The source node initiates a Route Request (RREQ) packet containing an anonymous global trapdoor and an onion. When a node receives the RREQ message it tries to open the trapdoor using its private key to check if it is the intended destination. Otherwise it generates a public/private key pair and replaces it's one time public key in the appropriate field in RREQ message and broadcasts the packet to its neighbors. The next node performs the same modification and records the one time public key of the previous node to use it in Route Error (RERR) phase. Each intermediate node will add its self-aware layer to the onion. ANODR is a reactive protocol [8]. ANODR prevents strong adversary from packet flow back to its source or destination.

\subsection{Ad-hoc On Demand Distance Vector (AODV)}

A. Rathinam et al (2008) [9] improved version of the AODV algorithm with route repair scheme, where if any link failure takes place the nodes in the active communication path between the source and the destination acts as virtual source and continues the search process to re-establish the communication. The AODV routing protocol is a dynamic, self starting protocol used in Mobile Ad-hoc Networks (MANET) which is basically a collection of mobile nodes that can communicate with each other. This routing protocol functions without any need for fixed infrastructure or base station. AODV routes are only established when it needed to reduce traffic overhead with small delay. That means, AODV supports Uncast, Broadcast and Multicast (UBM) without any further protocols. AODV is belongs to the class of Distance Vector Routing Protocols (DV). It is also expanded by routing flags, the interface, and a list of precursors and for outdated routes the last hop count is stored.

\subsection{Dynamic Source Routing protocol (DSR)}

The dynamic source routing protocol is an on demand routing protocol. And it is a simple and efficient routing protocol designed specifically for use in multi-hop wireless ad hoc networks of mobile nodes. DSR allows the network to be completely self-organizing and self-configuring, without the need for any existing network infrastructure or administration. The DSR protocol is composed of two main mechanisms that work together to allow the discovery and maintenance of source route in the ad hoc network. 


\subsection{Dynamic MANET On demand (DYMO)}

The Dynamic MANET On demand (DYMO) is a reactive or on demand, multihop, unicast routing protocol that not update route information periodically [10]. The basic operation of DYMO protocols to generates RREQ messages and floods them for Destination routers for whom it doesn't have route information. Intermediate nodes store a route to the originating router by adding it into its routing table during this dissemination Process. A RERR message is generated when a node receives a data packet for the destination for which route is not known or the route is broken. The source node reinitiate route discovery quickly as it receives this RERR. Hello messages are used by all nodes to maintain routes to its neighbor nodes. The sequence numbers are used by nodes to determine the order of route discovery messages and so avoid propagating stale route information.

\subsection{Landmark ad-hoc routing (LANMAR)}

LANMAR is an efficient routing protocol in a "flat" Ad- hoc network which combines the feature of Fisheye State Routing (FSR) and Landmark routing protocols. This protocol combines properties of link state and distance vector algorithm and builds subnets of groups of nodes which are likely to move together [11]. LANMAR helps to resolve both scalability and mobility problems in Ad-hoc networks while reducing bandwidth and storage overhead. Each node in wireless networks are maintains routing information only about nodes which lies within its scope and the landmark nodes. It is significantly reduces routing large ad-hoc networks. The landmark table maintains direct landmarks from all the subnets, respectively. table size and routing update overhead and thus scalable to routes to near-by destinations and routes to all the If destination is not present in node's scope, the logical subnet field of the destination is searched and packet is forwarded towards the landmark of destination's logical subnet.

\subsection{Inter-zone Routing Protocol (IERP)}

The Inter-zone Routing Protocol (IERP) is responsible for reactively discovering routes to the destination beyond a node's routing zone [12]. An IERP protocol is used where the destination is not found within the routing zone. The route request packets are transmitted to all border nodes, which in turn forward the request if the destination node is not found within their routing zone. IERP distinguish itself from standard flood search by implementing the concept, called border-casting. The border casting packet delivery service is provided by the Border-cast Resolution Protocol (BRP) [13]. The IERP takes the advantage of the local routing information provided by the IARP. When there is request for a route beyond the local zone, global route discovery is required.

\subsection{Zone Routing Protocol (ZRP)}

Zone Routing Protocol (ZRP) combines the advantages of both reactive and pro-active protocols into a Hybrid scheme, taking advantage of pro-active discovery within a node's local neighborhood, and using a reactive protocol for communication between these neighborhoods [14]. The ZRP is not so much a distinct protocol as it provides a framework for other protocols. The separation of a nodes local neighborhood from the global topology of the entire network allows for applying different approaches - and thus taking advantage of each technique's features for a given situation. These local neighborhoods are called zones each node may be within multiple overlapping zones, and each zone may be of a different size. The "size" of a zone is not determined by geographical measurement, but is given by a radius of length, where is the number of hops to the perimeter of the zone. Each component works independently of the other and they may use different technologies in order to maximize efficiency in their particular area.

\section{SIMULATION SETUP}

\subsection{Software}

QualNet is a modelling tool for wireless and wired network. QualNet is a state-of-the-art simulator for large, heterogeneous networks and the distributed applications that execute on such networks. QualNet is robust set of wired and wireless network protocol and device models, useful for simulating diverse types of networks. The QualNet suite is composed of QualNet Simulator, which claims to be the fastest for real-time traffic modeling. QualNet Animator allowed to graphically designing the network model (using a wide library of components) and it displays the results of simulation runs. QualNet designer allows creating Finite State Automata to describe the behavior of your network, while with QualNet Analyzer and Designer you can interpret and make sense of simulation results.

\subsection{Simulation setup}

The wireless Ad-hoc network has been setup as below given Fig.4

- Area of network- $100 \mathrm{~m} \times 100 \mathrm{~m}$

- $\quad$ No. of nodes -20 
- $\quad$ Network- 802.11b

- $\quad$ Application- FTP with CBR

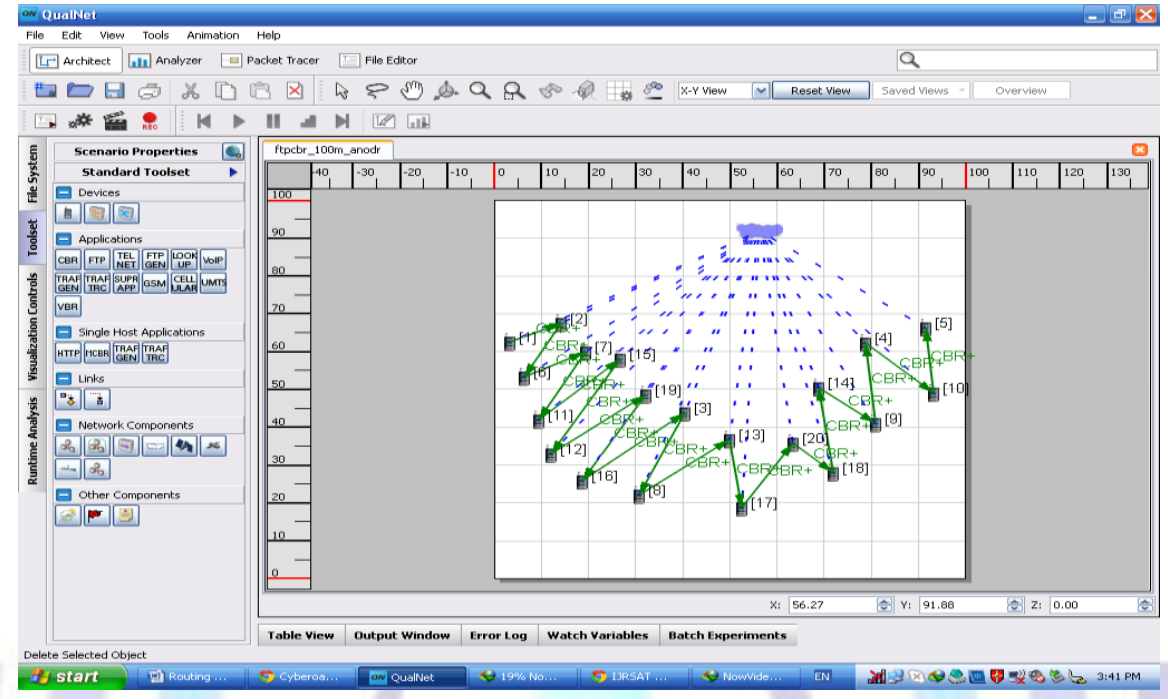

Fig. 4 Placement of number of nodes in Wireless LAN with ANODR routing protocols.

There are some matrices used to improve the QoS of Wireless Ad-hoc network as Average end-to-end delay, average jitter, average queue length, average queue time, throughput, average hops count and PDR.

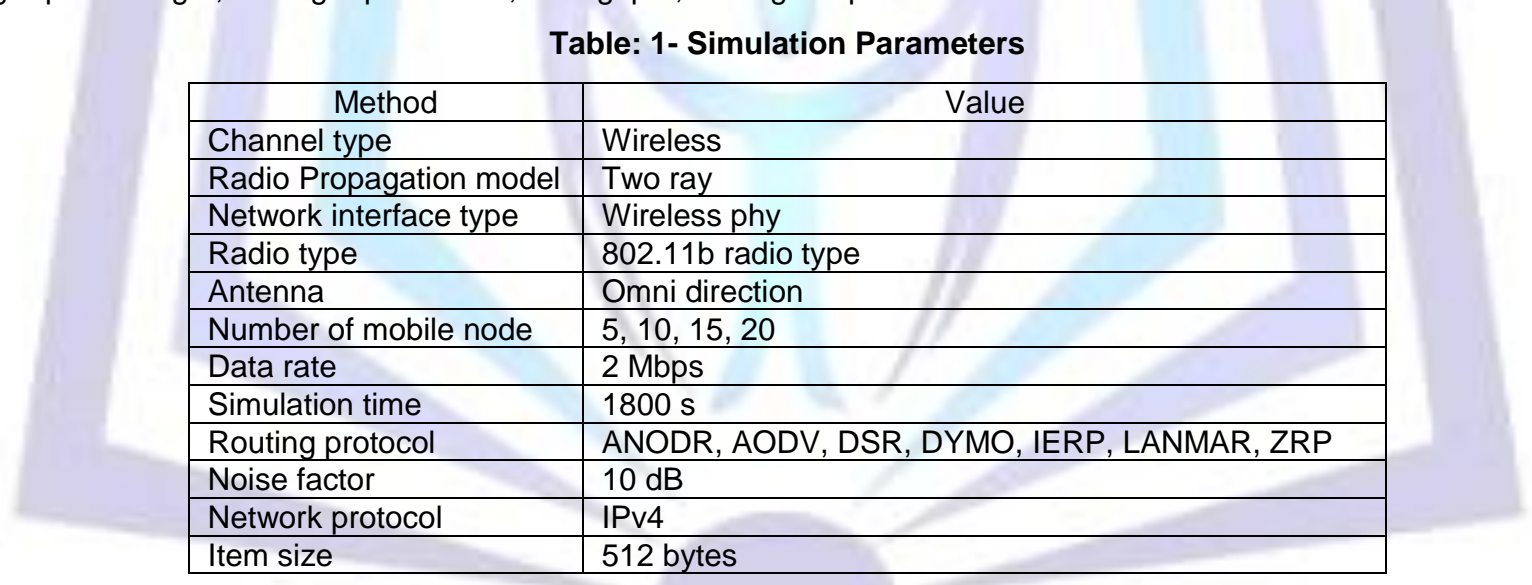

\section{RESULT}

\subsection{Average jitter}

Average Jitter is the variation (difference) of the inter-arrival times between the two successive packets received [14]. Table1 shows the average jitter variation in different routing protocols in wireless LAN. According to jitter variation, DSR provide better QoS with respect to other with increasing in no. of nodes. Average jitter is increased linear/fast in IERP LANMAR and ZRP as increased in no. of nodes from 1 to 20 with compare to other routing protocols as given in Fig 5 . The average jitter of ANODR, DSR, DYMO and AODV is increased slightly; due to this the performance of these protocols is better than other. 
Table: 2 Average Jitter for different routing protocols

\begin{tabular}{|l|l|l|l|l|}
\hline & 5 nodes & 10 nodes & 15 node & 20 nodes \\
\hline IERP & 0.190235 & 0.284641 & 0.376921 & 0.472488 \\
\hline ZRP & 0.058736 & 0.164256 & 0.189036 & 0.254323 \\
\hline LANMAR & 0.05849 & 0.108463 & 0.204809 & 0.259986 \\
\hline AODV & 0.036026 & 0.110602 & 0.077941 & 0.119515 \\
\hline DYMO & 0.029197 & 0.118151 & 0.089624 & 0.137209 \\
\hline ANODR & 0.028917 & 0.108517 & 0.079445 & 0.107375 \\
\hline DSR & 0.024719 & 0.117558 & 0.090532 & 0.120797 \\
\hline
\end{tabular}

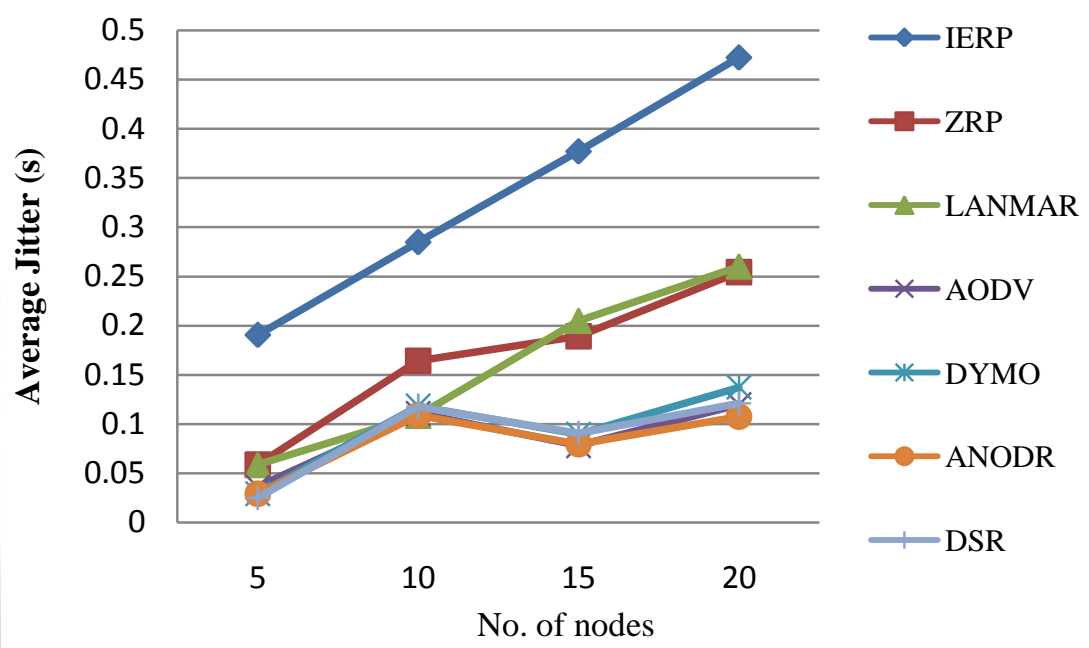

Fig. 5 Average Jitter (s) variation Wireless LAN by routing protocols

\subsection{Average end to end delay}

Average End to End Delay [15] can be defined as a measure of average time taken to transmit each packet of data from Source node to Destination node.

Table 3 shows the average end to end delay variation in different routing protocols in wireless LAN. According to jitter variation, DSR provide better QoS with respect to other with increasing in no. of nodes.

\section{Table 3 Average End to End Delay variation in different routing protocols}

\begin{tabular}{|l|l|l|l|l|}
\hline & 5 & 10 & 15 & 20 \\
\hline IERP & 0.486758 & 1.180565 & 1.301406 & 1.407832 \\
\hline LANMAR & 0.240059 & 0.362461 & 0.553394 & 0.857752 \\
\hline ZRP & 0.235574 & 0.476115 & 0.627354 & 0.812053 \\
\hline AODV & 0.152949 & 0.359108 & 0.252883 & 0.321625 \\
\hline ANODR & 0.148451 & 0.386374 & 0.259677 & 0.327373 \\
\hline DYMO & 0.144198 & 0.376539 & 0.283162 & 0.3666 \\
\hline DSR & 0.140841 & 0.359418 & 0.266805 & 0.34283 \\
\hline
\end{tabular}




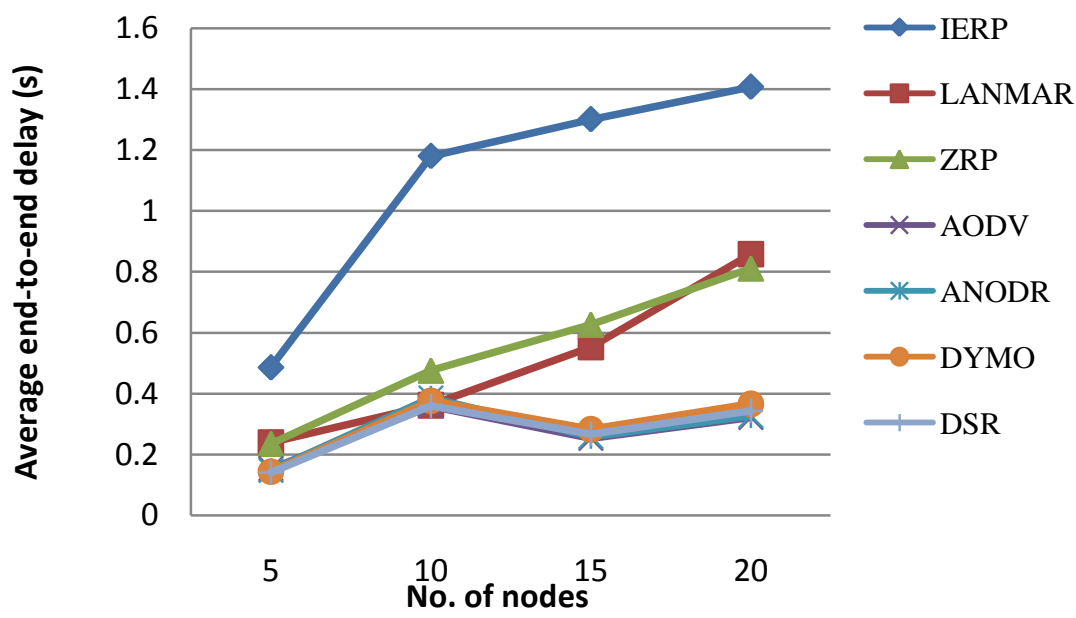

Fig.6 Variation in average end-to-end delay for Wireless LAN with FTP application

Average end-to-end delay is increased fast in IERP, ZRP and LANMAR as increased in no. of nodes from 1 to 20 with respect to other protocols. The average end-to-end delay is increased by $189.4 \%$ with increase no. nodes from 5 to 20 nodes by using IERP routing protocols in wireless local area network with $110.3 \%$ increase in average end-to-end delay by AODV protocols. The performance of WLAN network is improved better by using AODV, DSR and DYMO protocols as given in Fig.6.

\subsection{Throughput}

Throughput is the measure of the number of packets successfully transmitted to their final destination per unit time [16]. Throughput of Wireless LAN is better given by using AODV routing protocols with respect to others. The throughput variation in WLAN by using AODV protocols is low with increasing number of nodes as given Table 4. Throughput of Wireless LAN is high at all nodes for AODV routing protocols and IERP show the low throughput for all given node form 5 to 20 as given Fig. 7 . So the performance of AODV routing protocols is better than other routing protocols with variation in no. of nodes.

Table 4 Throughput (bit/s) variation in WLAN by using different routing protocols for FTP application

\begin{tabular}{|l|l|l|l|l|}
\hline & 5 nodes & 10 nodes & 15 nodes & 20 nodes \\
\hline AODV & 438941.6 & 271393.4 & 154034.5 & 127431.7 \\
\hline DSR & 313221.2 & 218967.9 & 111034.4 & 43031.18 \\
\hline ANODR & 238943.5 & 170548.1 & 64829.97 & 25019.48 \\
\hline LANMAR & 238705.1 & 168955.5 & 75342.53 & 51515.13 \\
\hline DYMO & 232703.7 & 159528.4 & 75928.4 & 50936.2 \\
\hline ZRP & 187108.2 & 111342.5 & 75196.03 & 54932.15 \\
\hline IERP & 158468.9 & 91656.6 & 37561.6 & 12689.23 \\
\hline
\end{tabular}




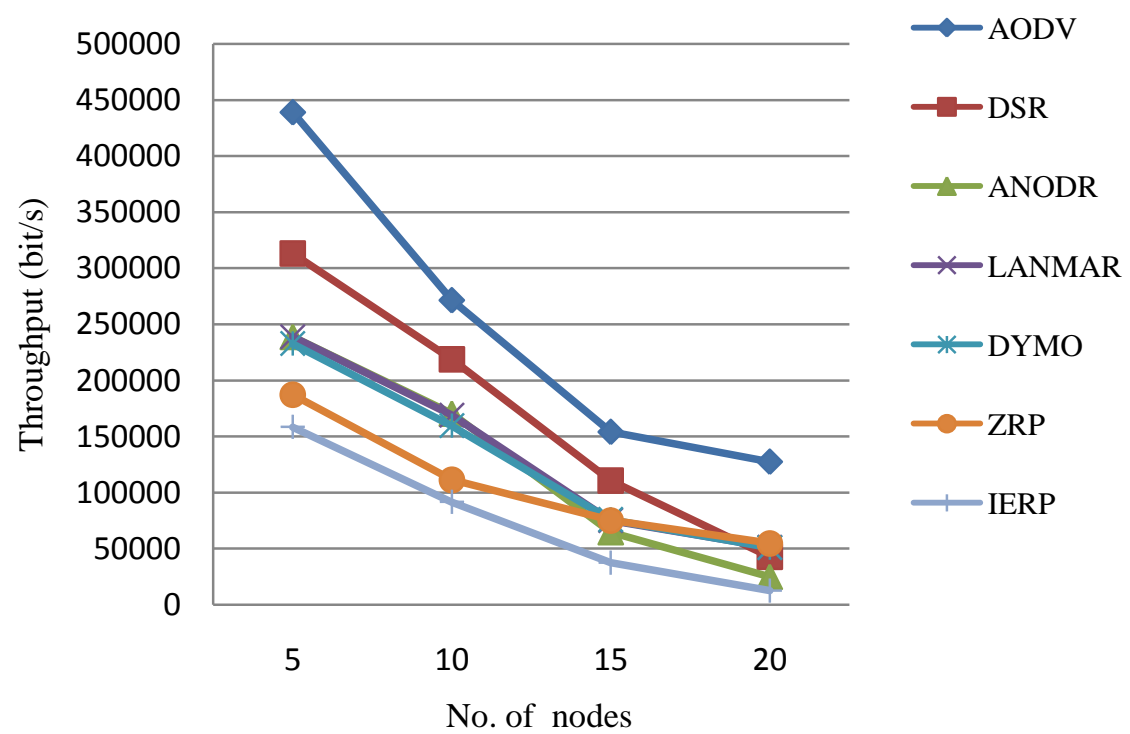

Fig. 7 Throughput variation in WLAN with routing protocols by using FTP

\subsection{Packet delivery ratio (PDR)}

Packet Delivery Ratio is defined as the ratio of the number of data packets successfully delivered to those generated by the source [17].

Packet Delivery Ratio $=(\text { Received packets/Sent Packets })^{*} 100$

Packet delivery is increased more by using LANMAR routing protocols than other protocols in wireless LAN as given Table 4 . When packet delivery ratio is increased than then the performance of wireless network is increased, so the LANMAR and AODV routing protocols provided the better quality of service to given wireless network with increased no. of nodes.

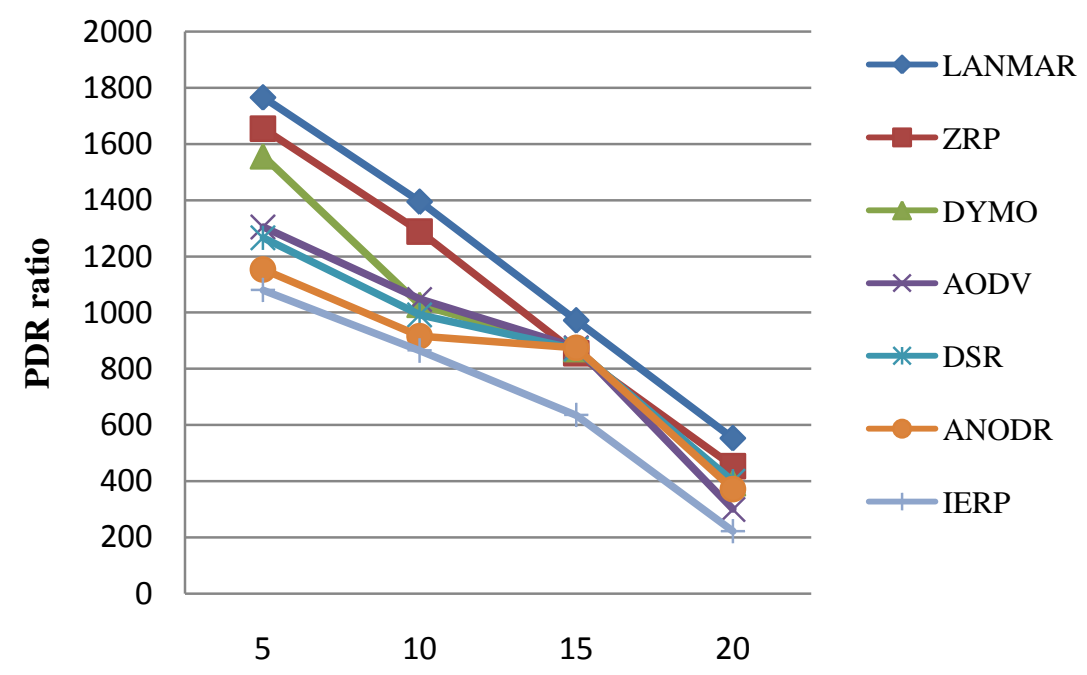

No. of nodes

Fig. 8 Packet delivery ratio in wireless LAN with different protocols 
Table 5: Packet delivery ratio for Wireless LAN with different routing protocols

\begin{tabular}{|l|l|l|l|l|}
\hline & 5 nodes & 10 nodes & 15 nodes & 20 nodes \\
\hline LANMAR & 1766.604 & 1394.851 & 972.2541 & 552.5008 \\
\hline ZRP & 1654.591 & 1288.595 & 855.2601 & 453.5542 \\
\hline DYMO & 1557.025 & 1028.125 & 870.5899 & 392.7775 \\
\hline AODV & 1304.984 & 1047.619 & 875.5409 & 300 \\
\hline DSR & 1266.418 & 992.425 & 869.8374 & 400 \\
\hline ANODR & 1153.92 & 916.186 & 875.0607 & 371.4286 \\
\hline IERP & 1080 & 864.8181 & 635.5072 & 222.2222 \\
\hline
\end{tabular}

The IERP routing protocols provided the poor QoS performance with respect to PDR in wireless LAN using increased no. of nodes as given Fig 8 . And AODV routing protocols have less variation in packet delivery with compare to other routing protocols.

\subsection{Average Queue length}

Average queue length in bytes reached by this queue during simulation. The average queue length is calculated as follows: average queue length $=$ sum of weighted packet sizes for all packets / (simulation time, in seconds), Where weighted packet size $=$ (packet size, in bytes) ${ }^{*}$ (time spent by the packet in the queue, in seconds)

Table 6 Variation of Average Queue length (bytes) in wireless LAN by different routing protocols

\begin{tabular}{|l|l|l|l|l|}
\hline & 5 nodes & 10 nodes & 15 nodes & 20 nodes \\
\hline IERP & 2393.36 & 1615.47 & 1582.56 & 924.258 \\
\hline DSR & 1841.69 & 1322.62 & 587.645 & 583.842 \\
\hline LANMAR & 1639.4 & 1273.21 & 591.816 & 607.697 \\
\hline ZRP & 1566.1 & 1258.09 & 1066.1 & 615.058 \\
\hline DYMO & 1482.03 & 1215.12 & 626.11 & 597.24 \\
\hline AODV & 444.985 & 572.601 & 572.83 & 595.592 \\
\hline ANODR & 421.068 & 477.625 & 599.635 & 634.886 \\
\hline
\end{tabular}

If average queue length of given network is high than that has provided less QoS performance. Here the average queue length is more by using IERP with other routing protocols as given in Table 6. AODV and ANODR routing protocols provided better QoS performance of Wireless LAN with respect to remaining routing protocols. The Queue length of AODV and ANODR is slightly increased but average length is decreased for other remaining routing protocols in wireless LAN as given in Fig. 9.

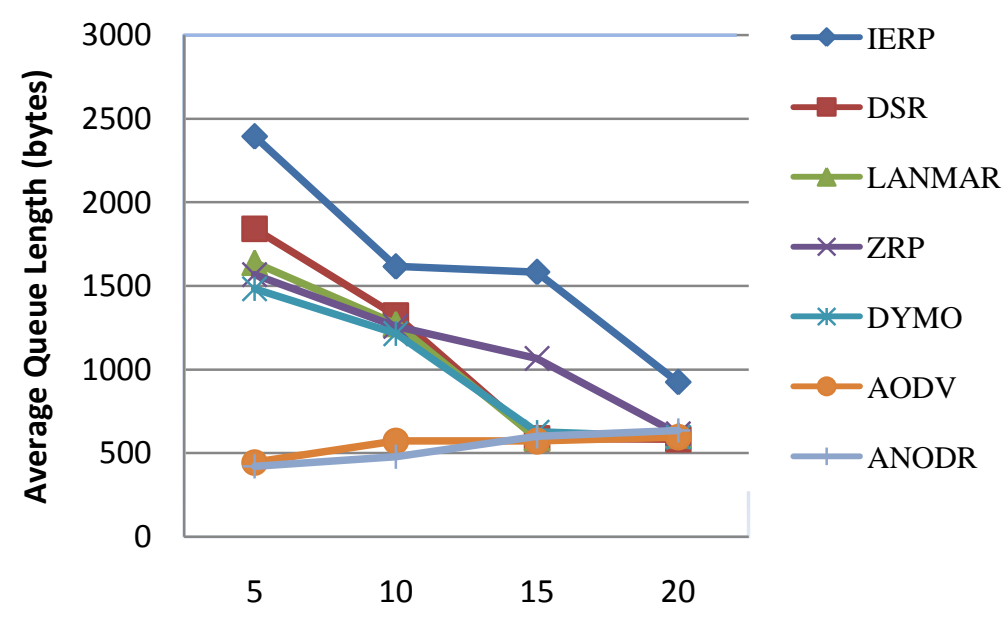

No. of nodes

Fig. 9 Average Queue Length (bytes) variation 


\subsection{Average Time in Queue}

Average delay in suffered by the packets in this queue (in seconds). The average time in queue is decreased slightly of wireless LAN by using AODV routing protocols with respect to LANMAR and ZRP routing protocols as fig. average queue time in queue is decreased by 0.364929 to 0.198164 in AODV routing protocols as given Table 7.The average time in queue is decreased for all routing protocols in Wireless LAN but AODV have less variation in Wireless LAN so AODV provide better performance to wireless network with respect to average time in queue as given Fig. 10.

Table 7 Average time in Queue variation Wireless LAN

\begin{tabular}{|l|l|l|l|l|}
\hline & 5 nodes & 10 nodes & 15 nodes & 20 nodes \\
\hline LANMAR & 0.696117 & 0.540021 & 0.402636 & 0.295388 \\
\hline ZRP & 0.6557 & 0.545974 & 0.446999 & 0.264722 \\
\hline DYMO & 0.617982 & 0.532142 & 0.311061 & 0.226627 \\
\hline DSR & 0.583942 & 0.487507 & 0.301946 & 0.154496 \\
\hline ANODR & 0.466033 & 0.267231 & 0.317147 & 0.101813 \\
\hline AODV & 0.364929 & 0.385549 & 0.304933 & 0.198164 \\
\hline IERP & 0.316178 & 0.227575 & 0.28306 & 0.14446 \\
\hline
\end{tabular}

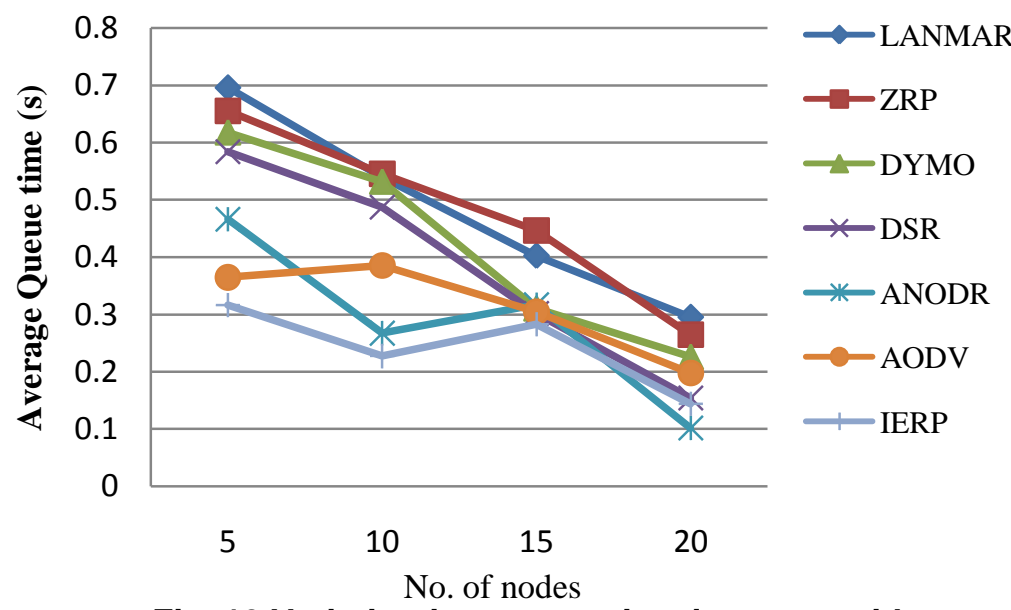

Fig. 10 Variation in average time in queue with different routing protocols in Ad-hoc network

Table 8 Average hops counts in Wireless LAN

\begin{tabular}{|c|c|c|c|c|}
\hline & 5 nodes & 10 nodes & 15 nodes & 20 nodes \\
\hline DSR & 64 & 56.035 & 41.095 & 31 \\
\hline ZRP & 54.971 & 52.8453 & 47.334 & 34.684 \\
\hline DYMO & 47.89 & 22.814 & 8.589 & 1.19933 \\
\hline LANMAR & 43.194 & 39.9867 & 18.562 & 6.749 \\
\hline ANODR & 18.705 & 11.3207 & 1.021 & 1.064 \\
\hline AODV & 11.411 & 4.39667 & 1.068 & 1.018 \\
\hline IERP & 2.024 & 2.326 & 1.892 & 1.69 \\
\hline
\end{tabular}




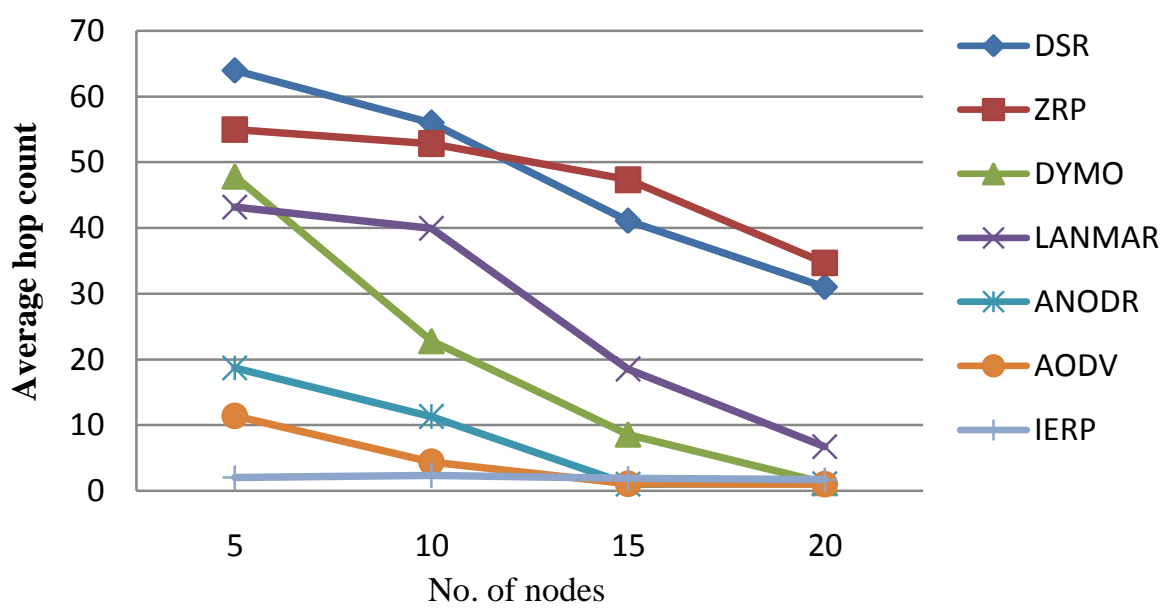

Fig. 11 Variation average hops counts in Ad-hoc network with different routing protocols

\section{CONCLUSION}

In this paper authors, study and compare the performance matrices as average jitter, throughput, packet delivery radio, average queue length, average time in queue and average end-to-end delay of wireless LAN with using different routing protocols i.e. ANODR, AODV, DSR, DYMO, IERP, LANMAR AND ZRP. Average Jitter of Wireless LAN is increased by using IERP routing protocols with compare to other protocols. But DSR protocols provided the low average jitter for WLAN networks with variation of no. of nodes. Average end-to-end delay is become high when we used IERP routing protocols in wireless local area networks. And DSR routing protocols provided less variation in average end to end delay with increasing of no. of nodes. AODV routing protocols performed the better throughput in wireless LAN with compare to other routing protocols. It means AODV give the better QoS for given wireless networks for FTP application. The Queue length is decreased in wireless LAN with IERP, DSR, and LANMAR, ZRP and DYMO and it is increased with ANODR and AODV. That means, AODV routing protocols improve the performance of WLAN with compare to other protocols. DSR routing protocols provided more hops count with increasing no. of nodes with respect to other routing protocols used in wireless LAN. With respect of all performance metrics, AODV routing protocols give better performance with compare to other routing protocols and it also improve the quality of service of wireless LAN. Authors' future work is to providing better security for Wireless network in different layers by using different routing protocols.

\section{REFERENCES}

1. M. Kumar and R. Rajesh, "A survey of mobile Ad-hoc reactive routing protocols in two different mobility models," International Journal of Engineering and Technology April 2009,Vol. 1, No. 1.

2. S. Das C. Perkins, E. Royer, "Ad hoc on demand distance vector (aodv) routing," Internet-Draft, draft-ietf-manet-aodv13.txt, February 2003, Work in progress.

3. Emilio Ancillotti, Raffaele Bruno, "Design and Performance Evaluation of Throughput-aware rate Adaptation protocols for IEEE 802.11 Wireless Networks", June 12, 1999.

4. J.L. Sobrinho and A.S. Krishnakumar, Real-time traffic over the IEEE 802.11 Medium Access Control layer, Bell Labs Technical Journal (1996) 172-187.

5. Dr.G.Padmavathi1, Dr.P.Subashini2, and Ms. D. Devi Aruna, "ANODR-ECC Key Management protocol with TELNET to secure Application and Network layer for Mobile Adhoc Networks", IJDPS, Vol.3, No.1, January 2012, pp 331-340

6. J.L. Sobrinho and A.S. Krishnakumar, Quality-of-Service in ad hoc carrier sense multiple access networks, IEEE Journal on Selected Areas in Communications 17(8) (1999) 1353-1368.

7. Dilli Ravilla, V. Sumalatha, Dr Chandra Shekar Reddy Putta, "Hybrid Routing Protocols for AD HOC Wireless Networks", IJASUC, Vol.2, No.4, December 2011, pp 79-96

8. Liu Yang, Markus Jakobsson, Susanne Wetzel, "Discount Anonymous On Demand Routing for Mobile Ad hoc Networks", IEEE, 2006, pp 1-6 
9. Jun Liu, Jiejun Kong, Xiaoyan Hong, Mario Gerla, "Performance Evaluation of Anonymous Routing Protocols in MANETs", WCNC , 2006, pp 646-651

10. Ahed Alshanyour and Uthman Baroudi, "Random and Realistic Mobility Models Impact on the Performance of BypassAODV Routing Protocol”, IEEE, 2008, pp 978-983

11. Jun Pan, Jianhua Li, "MASR: An Efficient Strong Anonymous Routing Protocol For Mobile Ad Hoc Networks", IEEE, 2009,pp1-7

12. Anitha Julian, A.Pravin Renold, V.Kalpana, C.P.Koushik, "E-Lanmar: Energy Aware Landmark Selection for Mobile Ad h oc Networks", ICCCI -2013, pp1-5

13. Md. Arafatur Rahman, Farhat Anwar, Jannatul Naeem, Md. Sharif Minhazul Abedin, "A Simulation Based Performance Comparison of Routing Protocol on Mobile Ad-hoc Network", ICCCE 2010, pp 1-5

14. Savita Gandhi SMIEEE, Nirbhay Chaubey MIEEE, Pathik Shah, Madhvi Sadhwani, "Performance Evaluation of DSR, OLSR and ZRP Protocols in MANETs", ICCCI -2012, pp 1-4

15. Julian Hsu, Sameer Bhatia, Mineo Takai, Rajive Bagrodia, "Performance of Mobile Ad HOC Networking Routing Protocols in Realistic Scenarios", IEEE, 2003, pp 1268-1275

16. Shailendra Kumar Pathak, Raksha Upadhyay, Rajdeep Shrivastava, "Performance Study of Ad-hoc Routing Protocols for IEEE802.11 and IEEE802.11e Standards", IEEE, 2012, pp 1-5

17. Sheeraz Ahmed, Muhammad Bilailr, Umer Farooq, Fazl-e-Hadi, "Performance Analysis of various routing strategies in Mobile Ad hoc Network using QualNet simulator", IEEE, 2007, 1-6

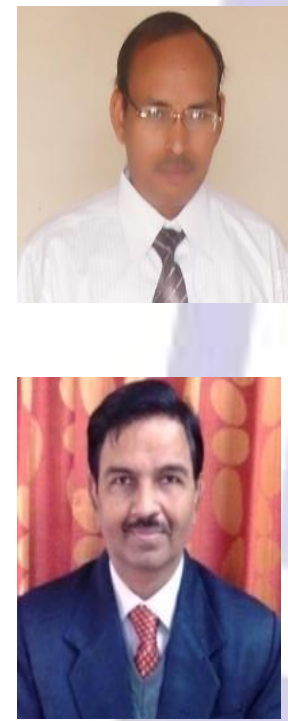

Mahendra Kumar was born in Agra, Uttar Pradesh, India on June $6^{\text {th }}$, 1981. He received B.Tech Degree in Electronics and Instrumentation Engineering from Hindustan College of Science and Technology Mathura Uttar Pradesh India in 2005 and M.Tech Degree in Engineering System from Dayalbagh Education Institute, Dayalbagh, Agra, Utter Pradesh, India in 2007. He is Research Scholar at Deptt. Of Instrumentation and Control Engineering, Dr. B. R. Ambedkar National Institute of Technology, Jalandhar, Punjab, India. He was JRF at IIT Delhi from 2007-2009. He was lecturer at Deptt. Of Instrumentation and Control Engineering, Dr. B. R. Ambedkar National Institute of Technology, Jalandhar, Punjab, India from July 2009 - Dec 2009. His research area of interest is modelling and simulation of wireless networks.

A.K. Jain received his B.E and M.E both from IIT, Roorkee, (erstwhile University of Roorkee, Roorkee) India in 1981 and 1987 respectively and received his Ph.D. degree on Quality of Service in High Speed Networks from the Dr. B. R. Ambedkar National Institute of Technology, Jalandhar, India in 2009. He has published over twenty-five research papers in national and international journals/conferences. He is presently working as Professor and Head in the Department of Instrumentation and Control Engineering, Dr. B. R. Ambedkar National Institute of Technology, Jalandhar, India. He is guiding Ph.D and M.Tech students in the area of Wireless Networks. Before joining N.I.T, Jalandhar, he has served at TIET Patiala, IET Lucknow, and NIT Hamirpur (Erstwhile REC Hamirpur) in various capacities. His research interests include quality of service in wireless networks, medium access protocols for mobile computing, and mesh networks. Dr. Jain is life member of ISTE India. 